\title{
Differential impact of impaired fasting glucose versus impaired glucose tolerance on cardiometabolic risk factors in multi-ethnic overweight/obese children
}

\author{
Mariska van Vliet • Roel P. Gazendam • Inès A. von Rosenstiel • Anton P. van Zanten • \\ Desiderius P. M. Brandjes • Jos H. Beijnen · Joost Rotteveel • Michaela Diamant
}

Received: 19 July 2010 / Accepted: 28 September 2010 /Published online: 20 October 2010

(C) The Author(s) 2010. This article is published with open access at Springerlink.com

\begin{abstract}
We aimed to investigate the prevalence of impaired fasting glucose (IFG) and impaired glucose tolerance (IGT), and their associations with cardiometabolic risk factors, according to ethnicity in a large obese paediatric cohort. A $75-\mathrm{g}$ oral glucose tolerance test was performed in 1,007 overweight/obese Dutch children of multi-ethnic origin, referred to the obesity outpatient clinics
\end{abstract}

Mariska van Vliet and Roel P. Gazendam contributed equally to this study.

M. van Vliet · I. A. von Rosenstiel

Department of Paediatrics, Slotervaart Hospital,

Amsterdam, The Netherlands

\section{J. H. Beijnen}

Department Pharmacy and Pharmacology, Slotervaart Hospital,

Amsterdam, The Netherlands

D. P. M. Brandjes

Department of Internal Medicine, Slotervaart Hospital, Amsterdam, The Netherlands

\section{A. P. van Zanten}

Department of Clinical Chemistry, Slotervaart Hospital, Amsterdam, The Netherlands

M. van Vliet $\cdot$ R. P. Gazendam • M. Diamant Department of Internal Medicine, Diabetes Centre,

VU University Medical Centre,

Haarlem, The Netherlands

\section{J. Rotteveel}

Department of Paediatrics, VU University Medical Centre,

Haarlem, The Netherlands

M. van Vliet $(\bowtie)$

Schermerstraat 9 rood,

2013EP Haarlem, The Netherlands

e-mail: ma.vanvliet@vumc.nl

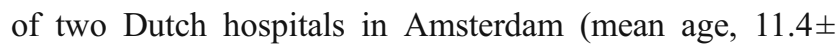
3.2 years; $50.7 \%$ boys). Anthropometric parameters and blood samples were collected, and cardiometabolic risk factors were assessed. The cohort consisted of Dutch native (26.0\%), Turkish (23.7\%), Moroccan (18.8\%) and children of 'other' (31.5\%) ethnicity. The prevalence of IFG was significantly higher in Moroccan and Turkish children as compared to Dutch native children $(25.4 \%$ and $19.7 \%$ vs. $11.8 \%$, respectively, $P<0.05$ ). IGT was most frequently present in Turkish and Dutch native children, relative to Moroccan children $(6.3 \%$ and $5.3 \%$ vs. $1.6 \%, P<0.05)$. Besides pubertal status and ethnicity, components of 'metabolic syndrome' (MetS) which were associated with IGT, independent of hyperinsulinaemia, were hypertension [odds ratio (OR), 2.3; 95\% CI, 1.1-4.9] while a trend was seen for high triglycerides (OR, 2.0; 95\% CI, 0.9-4.3). When analyzing components of MetS which were associated with IFG, only low high-density lipoprotein cholesterol was significantly associated (OR, 1.7; 95\% CI, 1.2-2.5) independent of hyperinsulinaemia. In conclusion, in a Dutch multi-ethnic cohort of overweight/obese children, a high prevalence of IFG was found against a low prevalence of IGT, which differed in their associations with cardiometabolic risk factors.

Keywords Obesity · Metabolic syndrome X · Children . Adolescents · Glucose metabolism disorders

\section{Introduction}

The global rise in the prevalence of obesity, due to adaptation of a Western lifestyle, has resulted in a high incidence of type 2 diabetes (T2DM) with the associated comorbidities and complications, particularly in popula- 
tions with an increased genetic susceptibility [19, 25, 27]. Several cardiometabolic risk factors may precede the development of aforementioned conditions, i.e. abdominal obesity, glucometabolic disorders, dyslipidaemia and hypertension. These entities are deemed to share (at least in part) similar pathophysiological backgrounds, since they often cluster within the so-called 'metabolic syndrome' (MetS) [29]. Although MetS has shown to be predictive for T2DM, especially the glucometabolic derangements impose a high risk to develop T2DM [8, 22]. Impaired fasting glucose (IFG) and impaired glucose tolerance (IGT) seem to differ with respect to their underlying mechanisms, with varying degrees of insulin sensitivity, insulin secretion and hepatic glucose output, as well as glucagon and incretin hormone levels $[12,28]$. Moreover, also differences are found between IFG and IGT as predictors for cardiometabolic outcome measures. Several studies have shown that 2-h glucose and IGT are stronger predictors of cardiometabolic events and mortality as compared to IFG $[10,11,30]$. Varying rates of prevalence for IFG and IGT are reported among both adult and paediatric populations. The National Health and Nutrition Examination Survey (NHANES) study showed IFG in $26 \%$ of the US population $\geq 20$ years, while in children (ages 12-19 years), IFG was present in $13.1 \%$ $(>5.6 \mathrm{mmol} / \mathrm{L})[6,20]$. In the diabetes epidemiology: collaborative analysis of diagnostic criteria in Europe (DECODE) study (ages 30-90 years), IGT was present in $2.9-24.6 \%$, highly dependent on age group [9], while the prevalence of IGT in children from the NHANES study was already 3.4\% [20]. Besides the data of the NHANES study, little data have been reported with respect to IFG and especially IGT in non-clinical populations (nonoverweight children) due to ethical concerns, and are largely limited to clinical cohorts, i.e. in an obese cohort of 164 children (ages 4-18 year), the prevalence of IGT was $22 \%$ [33]. These studies have also reported associations between prevalence rates and ethnicity. Previously, we found that Turkish children had a more adverse cardiometabolic risk profile than their peers of Moroccan origin, although results regarding differences in IFG versus IGT among ethnic groups remained inconclusive [38]. It is of importance to know how cardiometabolic risk factors vary per ethnic population to predict or explain differences in cardiometabolic outcomes in adulthood.

Since direct comparisons of glucometabolic derangements among ethnic groups are lacking, we aimed to investigate the prevalence of IFG and IGT according to ethnicity to identify children who might have increased risk for developing T2DM/cardiovascular disease (CVD) and to determine additional associated cardiometabolic risk for IFG and IGT in a large obese multi-ethnic paediatric cohort.

\section{Methods}

Study population and study protocol

Between March 2004 and June 2009, data were collected regarding overweight children (aged 3-18 years) who were referred to the obesity outpatient clinic of either an urban general hospital (Slotervaart Hospital, $n=659$ ) or an academic hospital (VU University Medical Centre, $n=348$ ) in Amsterdam, the Netherlands. Children were referred to one of the two hospitals by youth health care or general practitioners. Children were excluded from the study when diagnosed with secondary causes of obesity (i.e. hypothyroidism, hypogonadism and pituitary disorders or genetic syndromes), diabetes and/or when they used glucose- or lipid- lowering medication, corticosteroids or drugs acting on the central nervous system. None of the subjects had a history of alcohol abuse, and serologic tests for hepatitis $\mathrm{B}$ or $\mathrm{C}$ virus were all negative. During the first visit, a detailed history and physical examination was performed, including blood pressure measurements, height, weight and pubertal stage according to Tanner were assessed [35]. During the second visit, each child underwent an oral glucose tolerance test (OGTT; $1.75 \mathrm{~g} / \mathrm{kg}$ with a maximum of $75 \mathrm{~g}$ ). In addition, fasting blood samples were drawn for the assessment of insulin, lipid levels and alanine aminotransferase (ALT), a marker of non-alcoholic fatty liver disease [31]. Of the aforementioned tests, ALT was only determined in the Slotervaart Hospital $(n=659)$.

\section{Definitions}

Ethnicity was defined as Dutch if both parents were Dutch native and Moroccan or Turkish in cases where both parents were from that specific country. Children with other ethnicities and children with parents of different origins were collected in a separate group, hereafter referred to as the 'other' group. The 'ethnic minorities' group existed of all children who were not classified as Dutch natives. Body mass index (BMI) was standardized using Z-scores (Z-BMI) according to Dutch reference values [14].

IGT was defined as a 2 -h glucose $\geq 7.8$ and $<11.0 \mathrm{mmol} / \mathrm{L}$ and IFG was defined as a fasting glucose 5.6 to $6.9 \mathrm{mmol} / \mathrm{L}$ [41]. In case the values exceeded the upper limit of these ranges, diabetes was diagnosed. Insulin resistance was calculated according to the Homeostasis Model Assessment for Insulin Resistance (HOMA-IR): fasting plasma insulin (microunits per litre) $\times$ fasting glucose (millimoles per litre)/ 22.5 [23]. Insulin resistance was defined as HOMA-IR $\geq 3.5$ [18]. Hyperinsulinaemia was present when fasting plasma insulin was $\geq 90 \mathrm{pmol} / \mathrm{L}$ (prepubertal children) and $\geq 180 \mathrm{pmol} / \mathrm{L}$ (pubertal children) [39]. MetS was diagnosed according to a definition for children and adolescents as proposed by Weiss et al. [41] and was established when 
Table 1 Clinical and metabolic characteristics of overweight/obese subjects by ethnicity

\begin{tabular}{|c|c|c|c|}
\hline & Entire cohort & Children of Dutch origin & Children of ethnic origin \\
\hline Number & 1,007 & 262 & 745 \\
\hline Male $(\%)$ & 50.7 & 45.8 & 52.5 \\
\hline Pubertal (\%) & 58.5 & 52.7 & $60.5^{*}$ \\
\hline Age (years) & $11.4 \pm 3.2$ & $11.5 \pm 3.2$ & $11.4 \pm 3.2$ \\
\hline Z-BMI & $2.8 \pm 0.5$ & $2.7 \pm 0.6$ & $2.8 \pm 0.5^{*}$ \\
\hline Systolic blood pressure $(\mathrm{mmHg})$ & $116 \pm 13$ & $116 \pm 13$ & $116 \pm 13$ \\
\hline Diastolic blood pressure $(\mathrm{mmHg})$ & $69 \pm 9$ & $67 \pm 8$ & $69 \pm 9^{*}$ \\
\hline Fasting glucose $(\mathrm{mmol} / \mathrm{L})$ & $5.2 \pm 0.4$ & $5.1 \pm 0.4$ & $5.2 \pm 0.4^{*}$ \\
\hline Fasting insulin (pmol/L) & $110(72-162)$ & $110(67-153)$ & $110(74-167)$ \\
\hline HOMA-IR & $3.8(2.5-5.8)$ & $3.9(2.3-5.6)$ & $3.8(2.5-6.0)$ \\
\hline Total cholesterol (mmol/L) & $4.3 \pm 0.8$ & $4.3 \pm 0.8$ & $4.3 \pm 0.8$ \\
\hline HDL cholesterol (mmol/L) & $1.1(1.0-1.3)$ & $1.2(1.0-1.3)$ & $1.1(0.9-1.3)^{*}$ \\
\hline LDL cholesterol (mmol/L) & $2.6 \pm 0.7$ & $2.6 \pm 0.7$ & $2.7 \pm 0.7$ \\
\hline Triglycerides (mmol/L) & $0.8(0.6-1.2)$ & $0.9(0.6-1.2)$ & $0.8(0.6-1.2)$ \\
\hline $\operatorname{ALT}(\mathrm{IU} / \mathrm{L})^{\infty}$ & $22(17-29)$ & $22(17-27)$ & $22(17-29)$ \\
\hline \multicolumn{4}{|l|}{ Prevalence, $(\%)$} \\
\hline Z-BMI $>2$ (component of the metabolic syndrome) & 94.7 & 91.2 & 96.0 \\
\hline The metabolic syndrome & 15.4 & 10.3 & $17.2^{*}$ \\
\hline IFG & 16.3 & 13.4 & $19.2^{*}$ \\
\hline IGT & 4.9 & 4.7 & 5.3 \\
\hline High HDL cholesterol & 23.3 & 12.2 & $27.2^{*}$ \\
\hline High triglycerides & 19.5 & 18.7 & 19.7 \\
\hline Hypertension & 19.3 & 16.8 & 20.1 \\
\hline High ALT ${ }^{\mathrm{a}}$ & 11.1 & 9.2 & 11.5 \\
\hline High LDL cholesterol & 14.3 & 16.4 & 13.6 \\
\hline Insulin resistance & 54.1 & 56.6 & 54.8 \\
\hline
\end{tabular}

Data are expressed as mean $\pm \mathrm{SD}, N(\%)$ and median (interquartile range) for variables with a skewed distribution. Converting factors, Millimoles per litre to milligrams per decilitre: glucose, divide by 0.055 ; HDL/LDL cholesterol, divide by 0.0259 ; triglycerides, divide by 0.0113 . Millimoles per litre to international units per litre: insulin, divide by 6.945 . IFG - impaired fasting glucose, IGT - impaired glucose intolerance.

${ }^{\infty} N=657$

$* P<0.05$

${ }^{\mathrm{a}} N=657$

obesity (Z-BMI $>2$ corresponding with a BMI $\geq 97$ th percentile for age and sex) was present, in addition to two or more of the following criteria: a triglyceride level $\geq 95$ th percentile for age and sex, a high-density lipoprotein (HDL) cholesterol level $<5$ th percentile for age and sex, a mean (systolic or diastolic) blood pressure value $\geq 95$ th percentile for height and sex and IGT [43]. High low-density lipoprotein (LDL) cholesterol was considered present when levels were $\geq 95$ th percentile for age and sex [7], and high ALT levels above 30 IU/L [17, 37].

Biochemical analyses

Plasma glucose levels, total cholesterol, triglycerides and HDL cholesterol were measured by standardized validated methods
(SYNCHRON LX20, Beckman Coulter, USA and MODULAR ANALYTICS EVO solution, Roche, Belgium). LDL cholesterol was calculated by the Friedewald formula [15]. Plasma insulin levels were measured by an immunoluminometric assay (Immulite 200 system, DPC, Los Angeles, USA; intra-assay variation, 3-6\%; inter-assay variation, 3-5\%) and ADVIA Centaur insulin assay (Siemens, Netherlands; intraassay variation, 4.6\%; inter-assay variation, $6 \%$ ).

Statistical analyses

Mean (standard deviation, SD) or median (interquartile range, IQR) are shown after stratification for ethnicity. Differences were tested with $\chi^{2}$ analysis and ANCOVA (with adjustment for sex, ethnicity, pubertal status and 
Z-BMI). In comparing prevalence rates between groups, logistic regression with adjustment for confounding variables (sex, ethnicity, pubertal status and Z-BMI) was used. Multivariate logistic regression models were used to determine associations of IFG and/or IGT with cardiometabolic risk (using the NGT group as reference group). Results of these analyses are expressed as odds ratios (OR) and $95 \%$ confidence intervals $(95 \% \mathrm{CI})$. Interaction terms were built in order to determine significant interactions by ethnicity in the models. These were considered significant when $P<0.1$. In the models, the association of hyperinsulinaemia with IFG and IGT (instead of insulin resistance) was established, since HOMA-IR includes fasting glucose in its formula. A $P$ value $<0.05$ was considered statistically significant. All analyses were performed with SPSS, version 15.0 (for Windows).

\section{Results}

\section{Baseline characteristics}

Table 1 shows the baseline characteristics for children of Dutch origin and children of ethnic origin. The cohort consisted of 1,007 children (mean age $11.4 \pm 3.2$ years), of whom $50.7 \%$ were boys and $46.7 \%$ were prepubertal. The main ethnic groups were Dutch native (26.0\%), Turkish (23.7\%), Moroccan (18.8\%) and 'other' (31.5\%). The latter group consisted of over 23 ethnicities, with the largest subgroup being Surinamese. Almost all children (94.7\%) had a Z-BMI greater then 2 (the reference value of obesity in MetS) [43]. A total of $16.3 \%$ of subjects had IFG, whereas IGT was only present in $4.9 \%$ (see Table 1). Fourteen children $(1.4 \%)$ were detected who fulfilled both IFG and IGT criteria.

Relative to prepubertal children, pubertal children had a higher frequency of hypertension $(15.8 \%$ vs. $5.3 \%, P<$ $0.001)$, low HDL cholesterol levels $(50.6 \%$ vs. $38.8 \%, P<$ $0.001)$, high triglycerides $(10.5 \%$ vs. $5.5 \%, P<0.01)$, MetS $(25.8 \%$ vs. $12.4 \%, P<0.001)$ and insulin resistance (69.7\% vs. $34.6 \%, P<0.001)$, regardless of ethnicity.

Prevalence of IFG and IGT according to ethnicity

Figure 1 presents the prevalence rates of the glucometabolic abnormalities and various cardiometabolic risk factors according to ethnicity. There were no significant differences between Z-BMI between the presented groups. The prevalence of MetS was significantly higher in Turkish children relative to their peers of Moroccan and Dutch native origin. Subsequently, insulin resistance (as determined by HOMA-IR) was least frequently found in Moroccans (as compared to Dutch
Fig. 1 Prevalence of impaired fasting glucose, impaired glucose tolerance, metabolic syndrome, hypertension, low HDL cholesterol, high triglycerides, high LDL cholesterol, high ALT according to ethnicity; Dutch native (white bars), Turkish (light grey bars) and Moroccan (dark grey bars). ${ }^{*} P<0.05,{ }^{\infty} N=657$

native and Turkish children, 45.2 vs. $56.6 \%$ and $59.7 \%$, both $P<0.05)$.

Cardiometabolic risk factors according to glucometabolic status

Figure 2 shows the prevalence of cardiometabolic risk factors stratified for glucometabolic status in the entire cohort. No differences for the association models were observed between different ethnic groups (i.e. interaction terms in the models were not significant) Fig. 2.

Hyperinsulinaemia was present in $29.9 \%$ of children with NGT, against $50.6 \%$ in IFG children and $50.0 \%$ in IGT children (OR, 2.8; 95\% CI, 1.9-4.0 for IFG; OR, 1.8; $95 \%$ CI, 1.2-2.7 for IGT, respectively). Moreover, the small group with combined IFG and IGT showed $71.4 \%$ hyperinsulinaemia (OR of $5.9 ; 95 \% \mathrm{CI}, 1.8-19.6$, as compared to NGT).

Regarding the components of MetS, independent of hyperinsulinaemia, children with IGT more frequently showed hypertension (OR, 2.3; 95\% CI, 1.1-4.9), while a trend was seen for high triglycerides (OR, 2.0; 95\% CI, 0.9-4.3) as compared to NGT children. In contrast, IFG was associated with HDL cholesterol (IFG vs. NGT; OR, 1.7; 95\% CI, 1.2-2.5). Although the group who had both IFG and IGT showed the highest prevalence of components of the MetS, the association was only significant for hypertension (OR, 4.0; 95\% CI, 1.4-12.1) as compared to NGT.

\section{Discussion}

In a Dutch multi-ethnic cohort of predominantly obese children, a higher prevalence of IFG (16.3\%), rather than IGT (4.9\%) was found. IFG was associated with low HDL cholesterol while IGT was associated with hypertension, and a trend was seen towards significance for high triglycerides.

The prevalence of glucometabolic disorders in the present study is higher than recently reported in a study among 535 overweight/obese Italian children, which reported a prevalence of $7.7 \%$ for IFG and $3.2 \%$ for IGT [5]. In contrast, other studies among overweight/obese children showed lower prevalence rates for IFG (0.1$0.8 \%)$ while showing a higher prevalence for IGT (11.2$25 \%$ ), relative to our study $[3,32,33]$. The aforementioned 

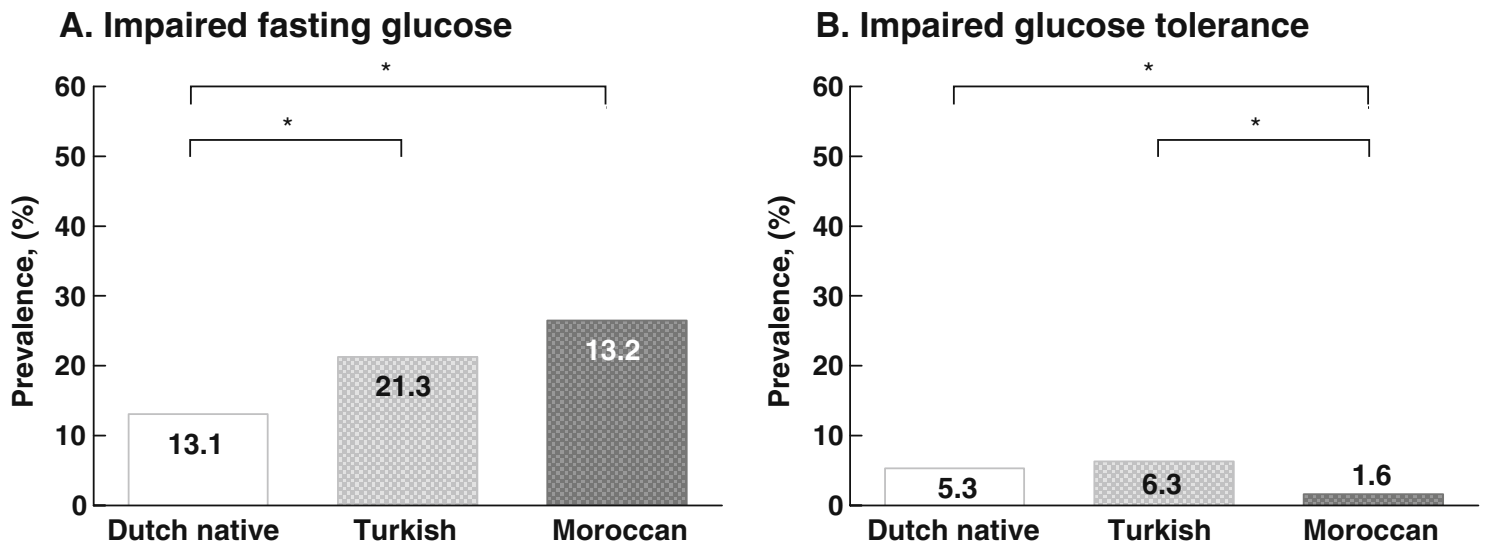

C. The metabolic syndrome

\section{Low HDL cholesterol}
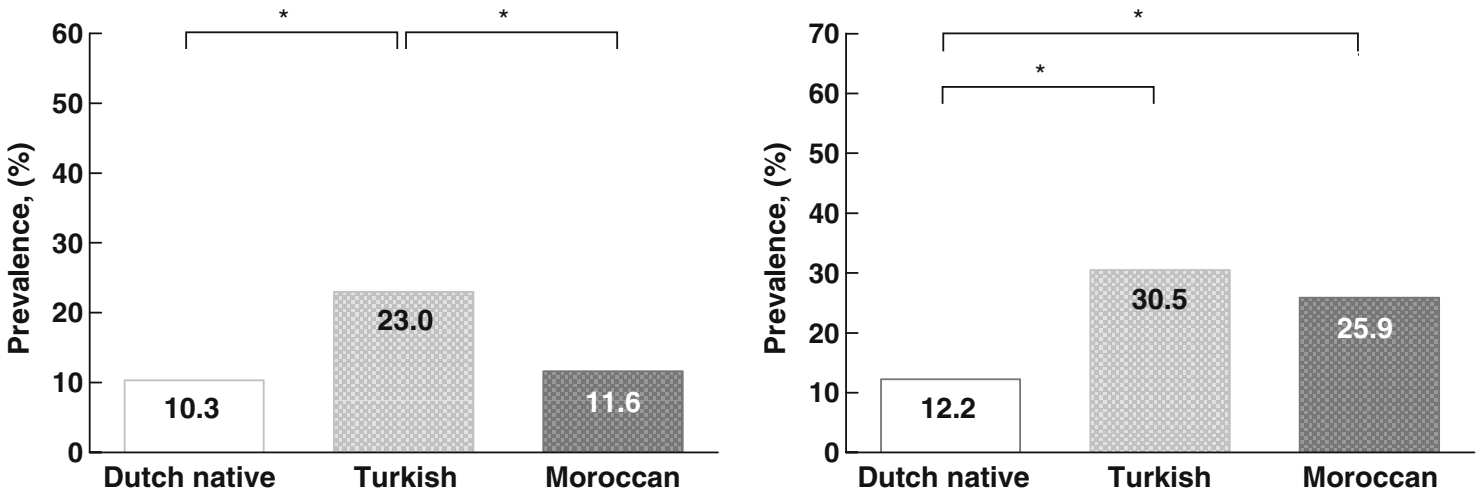

\section{E. High triglycerides}

\section{F. Hypertension}
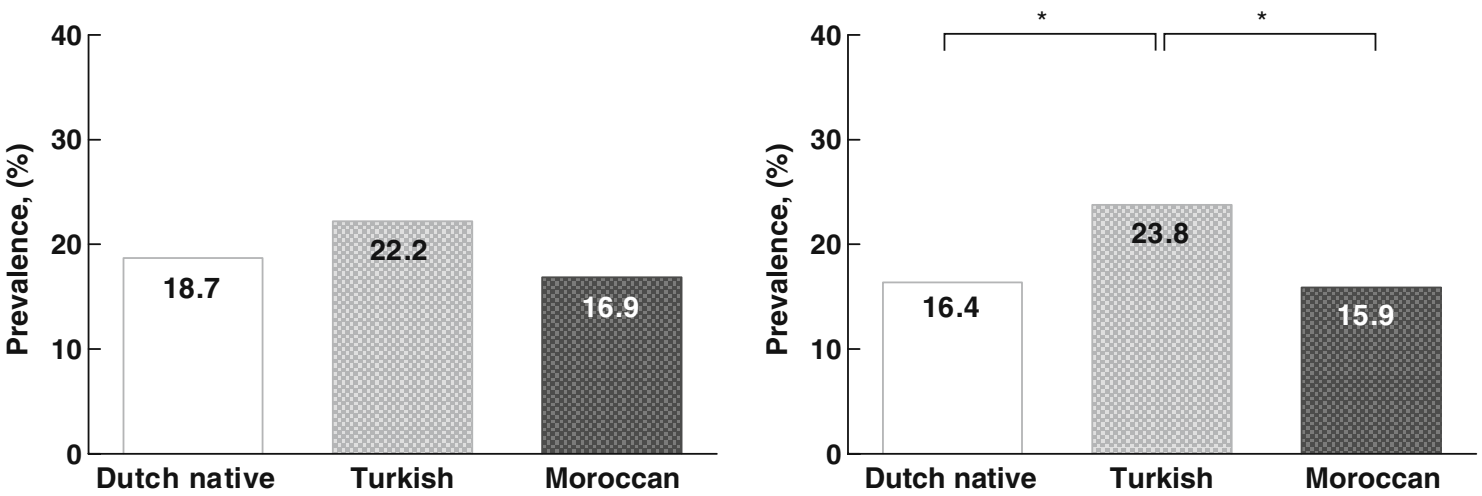

\section{G. High LDL cholesterol}

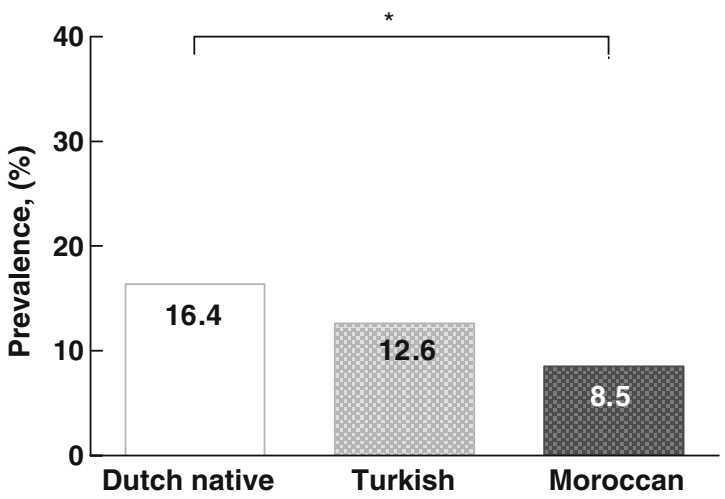

H. High ALT $^{\infty}$

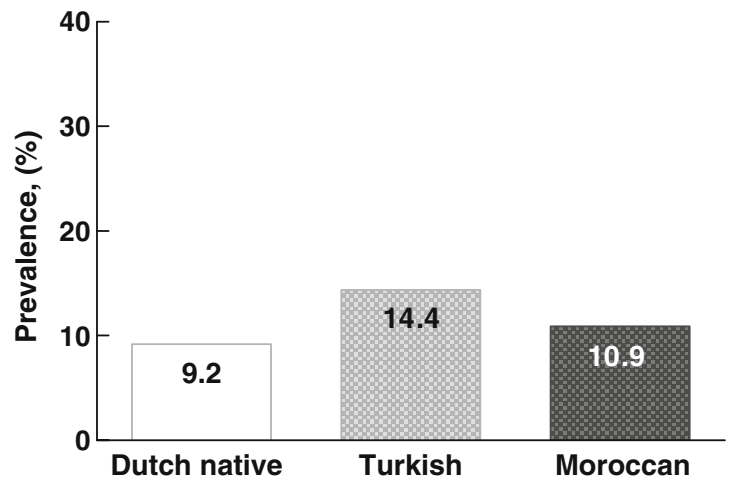


A. The metabolic syndrome

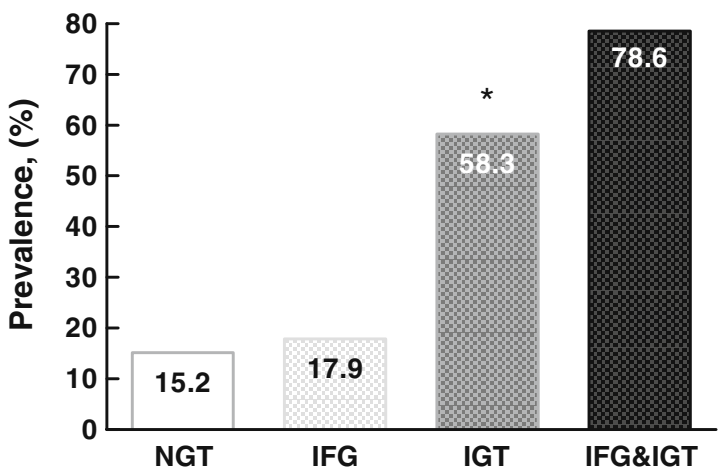

C. High triglycerides

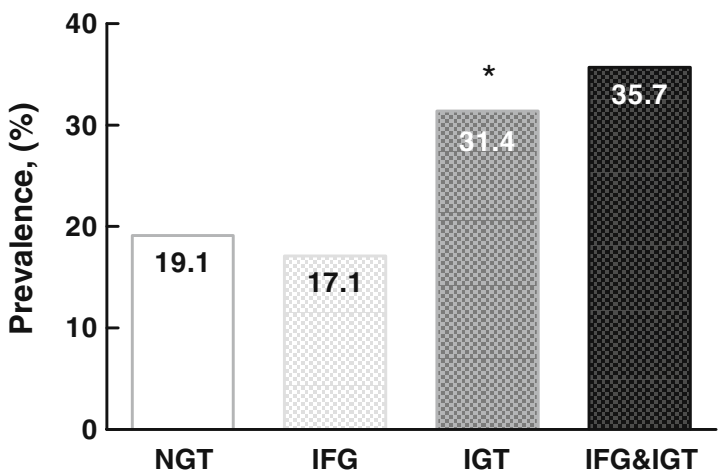

E. High $\mathrm{ALT}^{\infty}$

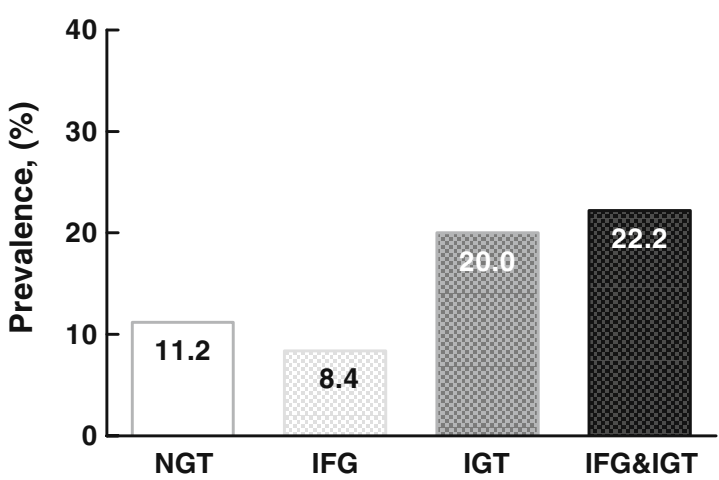

Fig. 2 Prevalence of the metabolic syndrome, hypertension, low HDL cholesterol, high triglycerides and high ALT according to glucometabolic status; normal glucose tolerance (white bars), impaired fasting

differences may be due to the variation in the Tanner stage of children among the studies [32] or by different lifestyles (i.e. Turkish and Moroccan people tend to eat more fruits and vegetables and less saturated fat as compared to Dutch natives) [4]; however, this would mean that Turkish children also would present with a more favourable risk profile. Therefore, it is likely that a great part of the difference is attributable to variation in genetic profile.

Turkish children showed the highest prevalence of IGT and insulin resistance, whereas IFG was most frequently

\section{B. Low HDL-cholesterol}

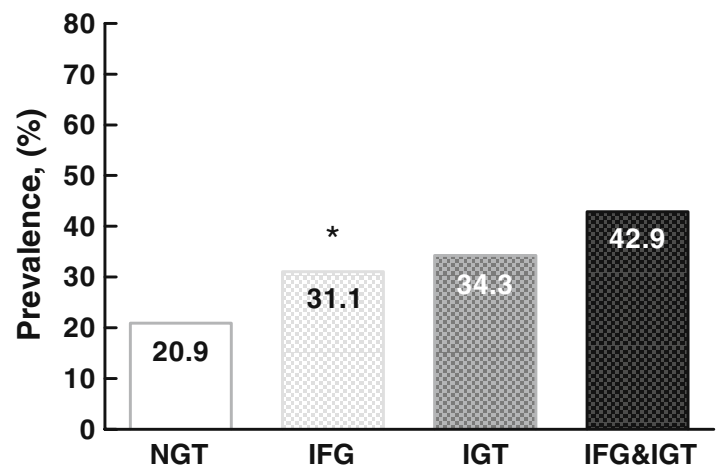

D. Hypertension

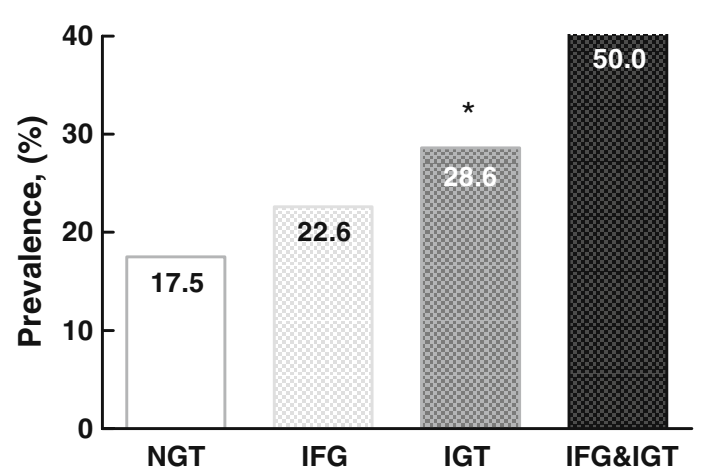

glucose (light grey bars), impaired glucose tolerance (dark grey bars) or presence of both (black bars). ${ }^{*} P<0.05,{ }^{\infty} N=657$

present in Moroccan children who showed the lowest prevalence of insulin resistance. The present study also found differences for other cardiometabolic risk factors among different ethnic groups and was able to show that Turkish children not only have a more adverse cardiometabolic risk profile as compared to Moroccan children, but also relative to Dutch native children.

Epidemiological studies report varying conclusions with respect to cardiometabolic health and ethnic minorities in adults; however, the social health service of Amsterdam 
confirmed a higher diabetes prevalence among people of Turkish and Moroccan origin (three and fourfold higher), next to higher glucose levels, more unfavourable ratio of total cholesterol, HDL cholesterol, but lower blood pressure values [2]. Moreover, a higher prevalence of CVD and T2DM among Turkish adults living in the Netherlands was found, in addition to a lower prevalence of CVD (despite a higher prevalence of T2DM at $>45$ years) among Moroccan people living in the Netherlands, as compared to the Dutch native population $[16,36]$. We have found that the cardiometabolic disadvantage in people of Turkish origin already starts in childhood, as Turkish children were shown to have a more adverse cardiometabolic risk profile as compared to Moroccan and Dutch native children.

The 'other' group generally showed prevalence rates which were close to the mean prevalence of the entire cohort, which is attributable to the heterogeneity of this group. However, impaired glucose tolerance was relatively often present, which probably results from the relatively high proportion Hindustani children. It is known that Hindustani people more frequently present with diabetes $[1,34]$.

Regarding cardiometabolic risk in IFG and IGT, our findings are partly in line with the outcome of the NHANES study, which showed significantly lower mean HDL cholesterol and higher mean systolic blood pressure, fasting plasma insulin and HOMA-IR levels among adolescents with IFG, relative to adolescents with NGT [20,21]. In addition, the strong association between IGT and hyperinsulinaemia was also confirmed by the latter study, which showed that insulin resistance played an important role in the pathogenesis of the transition from NGT to IGT [33]. Conversely, the association of elevated triglycerides and hypertension with IFG could not be established in the present article.

Differences in associations between IFG and IGT and cardiometabolic risk factors may in part be the result of the markedly higher prevalence of high ALT, (a marker of liver steatosis and hepatic insulin resistance), which was found among IGT relative to NGT children and is also associated with components of the metabolic syndrome in children [26, 37]. Moreover, they might be explained by the proposed differences in pathogenic mechanisms of IFG and IGT. In spite of some common denominators, IFG is more markedly associated with hepatic insulin resistance in the presence of (near) normal muscle insulin sensitivity, whereas IGT has been rather related to impaired muscle insulin sensitivity and normal to slightly reduced hepatic insulin resistance [24]. Still, both conditions are due to a decrease in acute beta-cell secretory response, as was also established in children [42]. Consequently, both IFG and IGT confer an increased risk of T2DM [40].
In the past, a difference between both glucometabolic derangements for cardiometabolic mortality has been reported, underlining the difference in pathophysiology of the two glucometabolic disorders. According to the DECODE study, increasing fasting glucose levels did not predict mortality while increasing 2-h glucose values showed an increase in mortality [11]. In another study, IFG predicted only overall death from all causes while IGT was predictive for death from all causes, in addition to CVD and coronary heart disease [11]. Moreover, it was concluded that only subjects who converted from IFG to T2DM had a higher risk of CVD mortality [30]. Until there is a definite answer to the question how glucometabolic disorders affect cardiometabolic risks and which role each glucometabolic disorder fulfills in the development of $\mathrm{T} 2 \mathrm{DM}$, one can only speculate with regard to the meaning of the finding of an unusual high prevalence of IFG in the present cohort. In addition, little information is available regarding the actual increased cardiometabolic risk of paediatric obesity; however, in a recent study among a large cohort of American Indian children, with a follow-up of 24 years, obesity, glucose intolerance and hypertension in childhood were strongly associated with increased rates of premature death from endogenous causes while hypercholesterolaemia was not identified as a major predictor [13].

This study has several limitations. First, due to the crosssectional design causal inferences between glucometabolic disorders, cardiovascular risk factors and ethnicity cannot be made. Moreover, due to lack of power, no significant associations between the presence of both IFG and IGT with cardiometabolic risk factors could be confirmed. In summary, in this retrospective study we found that glucometabolic disorders, in particular IFG more than IGT, are highly prevalent in overweight and obese Dutch children and adolescents of multi-ethnic origin. Turkish children showed the most adverse cardiometabolic risk profile, as compared to Dutch native and Moroccan children, which suggests an ethnic-specific difference in T2DM and CVD risk. IFG and IGT did not share similar associations with other components of MetS. Studies are warranted which investigate the long-term outcome of the presence of glucometabolic disorders in childhood on actual cardiometabolic risk concerning different ethnic paediatric populations.

Statement of competing interest The authors declare that they have no competing interests.

Open Access This article is distributed under the terms of the Creative Commons Attribution Noncommercial License which permits any noncommercial use, distribution, and reproduction in any medium, provided the original author(s) and source are credited. 


\section{References}

1. Bindraban NR, van Valkengoed I, Mairuhu G et al (2008) Prevalence of diabetes mellitus and the performance of a risk score among Hindustani Surinamese. African surinamese and ethnic dutch: a cross-sectional population-based study. BMC Public Health 8:271

2. Bos G, Jacobs-van der Bruggen M, Ujcic-Voortman J, et al (2007) Etnische verschillen in diabetes, risicofactoren voor hart- en vaatziekten en zorggebruik. RIVM rapport 260801002/2007

3. Brufani C, Ciampalini P, Grossi A et al (2010) Glucose tolerance status in 510 children and adolescents attending an obesity clinic in Central Italy. Pediatr Diab 11:47-54

4. Brussaard J, Brants H, van Erp-Baart A, Hulshof K, Kistenmaker C (1999) Voedselconsumptie en voedingstoestand bij 8-jarige Marokkaanse, Turkse en Nederlandse kinderen en hun moeders. Zeist, Report No.: TNO V99.1099

5. Cambuli VM, Incani M, Pilia S et al (2009) Oral glucose tolerance test in Italian overweight/obese children and adolescents results in a very high prevalence of impaired fasting glycaemia, but not of diabetes. Diab Metab Res Rev 25:528-534

6. Cowie CC, Rust KF, Byrd-Holt DD et al (2006) Prevalence of diabetes and impaired fasting glucose in adults in the U.S. population: national health and nutrition examination survey 1999-2002. Diab Care 29:1263-1268

7. de Man SA, Andre JL, Bachmann H et al (1991) Blood pressure in childhood: pooled findings of six European studies. J Hypertens 9:109-114

8. de Vegt F, Dekker JM, Jager A et al (2001) Relation of impaired fasting and postload glucose with incident type 2 diabetes in a Dutch population: the hoorn study. JAMA 285:2109-2113

9. The DECODE study group (2003) Age- and sex-specific prevalences of diabetes and impaired glucose regulation in 13 European cohorts. Diabetes Care 26:61-69

10. DECODE Study Group (1999) Glucose tolerance and mortality: comparison of WHO and American Diabetes Association diagnostic criteria. The DECODE study group. European Diabetes Epidemiology Group. Diabetes epidemiology: Collaborative analysis of diagnostic criteria in Europe. Lancet 354:617-621

11. DECODE Study Group (2001) Glucose tolerance and cardiovascular mortality: comparison of fasting and 2-hour diagnostic criteria. Arch Intern Med 161:397-405

12. Faerch K, Vaag A, Holst JJ et al (2009) Natural history of insulin sensitivity and insulin secretion in the progression from normal glucose tolerance to impaired fasting glycemia and impaired glucose tolerance: the Inter99 study. Diab Care 32:439-444

13. Franks PW, Hanson RL, Knowler WC et al (2010) Childhood obesity, other cardiovascular risk factors, and premature death. $\mathrm{N}$ Engl J Med 362:485-493

14. Fredriks AM, van Buuren S, Wit JM et al (2000) Body index measurements in 1996-7 compared with 1980. Arch Dis Child $82: 107-112$

15. Friedewald WT, Levy RI, Fredrickson DS (1972) Estimation of the concentration of low-density lipoprotein cholesterol in plasma, without use of the preparative ultracentrifuge. Clin Chem 18:499 502

16. Garssen J, Bos V, Kunst A et al (2003) Sterftekansen en doodsoorzaken van niet-Westerse allochtonen. CBS bevolkingstrends 2003:12-27

17. Kavey RE, Daniels SR, Lauer RM et al (2003) American heart association guidelines for primary prevention of atherosclerotic cardiovascular disease beginning in childhood. Circulation 107:1562-1566

18. Keskin M, Kurtoglu S, Kendirci M et al (2005) Homeostasis model assessment is more reliable than the fasting glucose/insulin ratio and quantitative insulin sensitivity check index for assessing insulin resistance among obese children and adolescents. Pediatrics 115:e500-e503

19. Kopelman PG (2000) Obesity as a medical problem. Nature 404:635-643

20. Li C, Ford ES, Zhao G et al (2009) Prevalence of pre-diabetes and its association with clustering of cardiometabolic risk factors and hyperinsulinemia among U.S. adolescents: national health and nutrition examination survey 2005-2006. Diab Care $32: 342-347$

21. Liu J, Joshi D, Sempos CT (2009) Non-high-density-lipoprotein cholesterol and cardiovascular risk factors among adolescents with and without impaired fasting glucose. Appl Physiol Nutr Metab 34:136-142

22. Lorenzo C, Okoloise M, Williams K et al (2003) The metabolic syndrome as predictor of type 2 diabetes: the San Antonio heart study. Diab Care 26:3153-3159

23. Matthews DR, Hosker JP, Rudenski AS et al (1985) Homeostasis model assessment: insulin resistance and beta-cell function from fasting plasma glucose and insulin concentrations in man. Diabetologia 28:412-419

24. Meyer C, Pimenta W, Woerle HJ et al (2006) Different mechanisms for impaired fasting glucose and impaired postprandial glucose tolerance in humans. Diab Care 29:1909-1914

25. Must A, Jacques PF, Dallal GE et al (1992) Long-term morbidity and mortality of overweight adolescents. A follow-up of the Harvard Growth Study of 1922 to 1935. N Engl J Med 327:1350 1355

26. Nathan DM, Davidson MB, DeFronzo RA et al (2007) Impaired fasting glucose and impaired glucose tolerance: implications for care. Diab Care 30:753-759

27. Ogden CL, Carroll MD, Curtin LR et al (2006) Prevalence of overweight and obesity in the United States, 1999-2004. JAMA 295:1549-1555

28. Petersen JL, McGuire DK (2005) Impaired glucose tolerance and impaired fasting glucose-a review of diagnosis, clinical implications and management. Diab Vasc Dis Res 2:9-15

29. Reaven GM (1988) Banting lecture 1988. Role of insulin resistance in human disease. Diabetes 37:1595-1607

30. Rijkelijkhuizen JM, Nijpels G, Heine RJ et al (2007) High risk of cardiovascular mortality in individuals with impaired fasting glucose is explained by conversion to diabetes: the Hoorn study. Diab Care 30:332-336

31. Schindhelm RK, Diamant M, Dekker JM et al (2006) Alanine aminotransferase as a marker of non-alcoholic fatty liver disease in relation to type 2 diabetes mellitus and cardiovascular disease. Diab Metab Res Rev 22:437-443

32. Shalitin S, Abrahami M, Lilos P et al (2005) Insulin resistance and impaired glucose tolerance in obese children and adolescents referred to a tertiary-care center in Israel. Int $\mathrm{J}$ Obes 29:571-578 (Lond)

33. Sinha R, Fisch G, Teague B et al (2002) Prevalence of impaired glucose tolerance among children and adolescents with marked obesity. N Engl J Med 346:802-810

34. Sumner AE (2009) Ethnic differences in triglyceride levels and high-density lipoprotein lead to underdiagnosis of the metabolic syndrome in black children and adults. J Pediatr $155: \mathrm{S} 7-\mathrm{S} 11$

35. Tanner T (2009) Growth at adolescents: with a general consideration of the effects of hereditary and environmental factors upon growth and maturation from birth to maturity, 2nd edn. Blackwell Scientific, Oxford

36. Van Leest L, van Dis D, Verschuren W (2002) Hart en vaatziekten bij allochtonen in Nederland. Een cijfermatige verkenning naar leefstijl- en risicofactoren, ziekte en sterfte: RIVM rapport Bilthoven 
37. van Vliet M, von Rosenstiel I, Schindhelm RK et al (2009) The association of elevated alanine aminotransferase and the metabolic syndrome in an overweight and obese pediatric population of multi-ethnic origin. Eur J Pediatr 168:585591

38. van Vliet M, von Rosenstiel I, Schindhelm RK et al (2009) Ethnic differences in cardiometabolic risk profile in an overweight/obese paediatric cohort in the Netherlands: a cross-sectional study. Cardiovasc Diabetol 8:2

39. Viner RM, Segal TY, Lichtarowicz-Krynska E et al (2005) Prevalence of the insulin resistance syndrome in obesity. Arch Dis Child 90:10-14
40. Wang JJ, Yuan SY, Zhu LX et al (2004) Effects of impaired fasting glucose and impaired glucose tolerance on predicting incident type 2 diabetes in a Chinese population with high postprandial glucose. Diab Res Clin Pract 66:183-191

41. Weiss R, Dziura J, Burgert TS et al (2004) Obesity and the metabolic syndrome in children and adolescents. N Engl J Med 350:2362-2374

42. Weiss R, Dziura JD, Burgert TS et al (2006) Ethnic differences in beta cell adaptation to insulin resistance in obese children and adolescents. Diabetologia 49:571-579

43. Zimmet P, Alberti G, Kaufman F et al (2007) The metabolic syndrome in children and adolescents. Lancet 369:2059-2061 